\title{
JOURNAL OF BUSINESS
}

MANAGEMENT AND ACCOUNTING

http://e-journal.uum.edu.my/index.php/jbma

How to cite this article:

Sieng, L.W. \& Azman M., (2021). Faktor-faktor mempengaruhi prestasi pekerja mengikut perspektif pekerja. Journal of Business Management and Accounting, 11(1), 87-107. https://doi.org/10.32890/jbma2021.11.1.5

\section{FAKTOR-FAKTOR MEMPENGARUHI PRESTASI PEKERJA MENGIKUT PERSPEKTIF PEKERJA}

\author{
Factors Affecting Employees' Performance \\ based on Employees' Perspective \\ ${ }^{1}$ Maisarah Azman \& ${ }^{2}$ Lai Wei Sieng \\ ${ }^{1 \& 2}$ Faculty of Economics and Management \\ Universiti Kebangsaan Malaysia \\ ${ }^{2}$ Corresponding author:laiws@ukm.edu.my
}

Received: 23/3/2020 Revised: 23/9/2020 Accepted: 3/1/2021 Published:31/1/2021

\begin{abstract}
ABSTRAK
Prestasi organisasi bergantung sepenuhnya kepada prestasi kerja yang ditonjolkan oleh pekerja. Kegagalan organisasi untuk mengekalkan prestasi kerja yang baik membawa kepada masalah isu kadar pusing ganti pekerja yang tinggi yang seterusnya menjejaskan produktiviti syarikat dan ekonomi negara. Objektif kajian ini adalah untuk mengenal pasti faktor-faktor yang mempengaruhi prestasi kerja dalam kalangan penjawat awam dan swasta di kawasan sekitar Lembah Klang. Data primer diperoleh melalui soal selidik dengan sejumlah 139 responden yang terlibat dalam kajian ini. Analisis faktor digunakan untuk menganalisis data yang sekadar diperoleh. Hasil kajian mendapati pekerja berpendapat bahawa ketiga-tiga faktor, iaitu
\end{abstract}


motivasi, persekitaran tempat kerja serta latihan dan pembangunan mempengaruhi prestasi kerja. Pihak organisasi perlu mengutamakan keperluan motivasi intrinsik kepada pekerja dan menetapkan matlamat latihan yang dijalankan dengan jelas untuk meningkatkan prestasi kerja.

Kata kunci: Prestasi pekerja, motivasi, persekitaran tempat kerja, latihan dan pembangunan

\section{ABSTRACT}

Organizational performance depends entirely on the performance of employees. The failure of the organization to maintain good employee performance leads to the problem of high turnover rate which in turn affects the productivity of the company and the national economy. The objective of this study is to identify the factors that influence employees' performance among employees in the area around the Klang Valley. Primary data were obtained through questionnaire approach with a total of 139 respondents who were involved in this study. Factor analysis was used to analyze the data obtained. The results of the study found that employees think that three factors, namely motivation, workplace environment as well as training and development affect their performance. Organizations need to prioritize the need for intrinsic motivation to employees and set clear training goals to improve employees' performance.

Keywords: Employee performance, motivation, workplace environment, training and development

\section{PENGENALAN}

Setiap organisasi mempunyai pelbagai jabatan untuk beroperasi seperti kewangan, pengeluaran, pemasaran dan sebagainya. Jabatan-jabatan ini memerlukan sumber manusia untuk mengisi kekosongan jawatan, menjalankan tugas masing-masing untuk mencapai matlamat yang disasarkan. Sumber manusia merujuk kepada ketersediaan manusia dari segi kuantiti dan kualiti yang digunakan apabila diperlukan (Rahmah Ismail, 2018). Sumber manusia diiktiraf sebagai elemen yang penting dalam mempengaruhi prestasi organisasi termasuk 
keuntungan yang sangat bergantung terhadap prestasi kerja (Ong dan Koh, 2018).

Organisasi menguruskan sumber manusia melalui dua cara, iaitu pengurusan sumber manusia dan pembangunan sumber manusia (Haslinda, 2009). Pengurusan sumber manusia merupakan proses pengurusan bakat manusia untuk mencapai objektif organisasi (Haslinda, 2009). Manakala pembangunan sumber manusia merupakan proses meningkatkan kualiti sumber manusia dan membolehkan mereka melakukan sesuatu dengan lebih efisien (Rahmah Ismail, 2018). Dua cara ini diperlukan untuk meningkatkan kecekapan, daya saing dan mengubah tingkah laku pekerja. Selain itu, kedua-dua pendekatan ini juga harus diambil kira oleh organisasi agar dapat menjadikan sumber manusia sebagai modal insan. Modal insan merupakan bentuk pelaburan yang sering digunakan untuk tujuan pendidikan, kesihatan dan kapasiti manusia yang lain yang dapat meningkatkan produktiviti apabila ditingkatkan (Todaro \& Smith, 2015). Menurut Haslinda (2009), modal insan merupakan satu aset yang bernilai dan boleh ditingkatkan melalui pelaburan.

Pengurusan dan pembangunan sumber manusia oleh organisasi akan mempengaruhi prestasi kerja. Menurut Elvina dan Liu Zhi Chao (2019), prestasi kerja bermaksud semua tingkah laku pekerja terlibat semasa bekerja. Nur Zainie dan Narehan (2015) mendefinisikan prestasi kerja sebagai pencapaian tugasan atau kemahiran yang berkaitan dengan kerja oleh pekerja. Pengurusan prestasi pekerja menjadi semakin penting dan diberi perhatian oleh sebab modal insan ialah penggerak utama dalam menerajui keupayaan organisasi merancang dan melaksanakan dengan baik dan berkesan (Mohtar Abas, 2006). Prestasi kerja merupakan indikator yang penting untuk melihat sejauh mana pekerja melaksanakan kerja mereka sama ada baik atau sebaliknya. Prestasi kerja juga mempunyai kaitan dengan perkara lain seperti kepuasan kerja, motivasi kerja, prestasi organisasi, kadar perolehan pekerja dan sebagainya. Vosloban (2012) mendapati bahawa prestasi pekerja memainkan peranan signifikan terhadap pertumbuhan organisasi sekiranya pekerja memahami peranan mereka dan pelaksanaan secara berterusan dari segi kemahiran komunikasi, kerja berpasukan, integriti dan sebagainya selaras dengan matlamat organisasi.

Peranan organisasi untuk mengekalkan prestasi kerja yang baik bukanlah sesuatu yang mudah. Strebler (2004) menyatakan antara 
punca prestasi pekerja yang tidak memberangsangkan adalah organisasi mengabaikan kebajikan pekerja (menyebabkan pekerja tiada dorongan untuk meningkatkan prestasi kerja. Selain itu, persekitaran tempat kerja yang tidak sesuai serta tiada persefahaman antara majikan dan pekerja juga turut mempengaruhi prestasi kerja. Prestasi pekerja juga tidak begitu memberangsangkan akibat daripada sesetengah organisasi yang kurang melabur dalam latihan dan pembangunan kepada pekerja dengan alasan ia menelan perbelanjaan yang mahal untuk melatih pekerja dan akhirnya organisasi akan mengalami kerugian setelah pekerja tersebut mendapat tawaran pekerjaan yang lebih baik dan mengambil keputusan untuk berhenti kerja. Kesulitan yang dihadapi di atas menyebabkan organisasi menghadapi isu kadar pusing ganti pekerja yang tinggi dan menghadapi kesukaran untuk mengekalkan pekerja. Antara punca-punca pusing ganti pekerja berlaku adalah disebabkan oleh faktor peribadi dan sikap pekerja, kurangnya pengiktirafan serta kemajuan kerjaya dan komunikasi yang tidak efektif antara pekerja dan pihak pengurusan (Iqbal, 2010).

Masalah lain yang wujud di tempat kerja seperti kepelbagaian, komunikasi, persekitaran tempat kerja, penyelesaian konflik dan pertikaian, kekurangan pengetahuan dan informasi serta pengurusan masa menyebabkan pekerja mengambil keputusan untuk berhenti kerja dan mengeluh kepada pihak atasan atau majikan mereka (Kapur, 2018). Sekiranya masalah-masalah di atas tidak diatasi dengan segera, prestasi pekerja akan merosot seterusnya mempengaruhi produktiviti syarikat dan menjejaskan ekonomi negara. Isu ini merupakan satu masalah yang besar. Maka, objektif kajian artikel ini adalah untuk mengenal pasti faktor-faktor yang mempengaruhi prestasi kerja dalam kalangan penjawat awam dan swasta di kawasan sekitar Lembah Klang mengikut perspektif pekerja. Penulisan artikel ini dibahagikan kepada lima bahagian, dimulai dengan bahagian 1, iaitu pengenalan yang merangkumi isu kajian. Bahagian 2 pula menyentuh mengenai sorotan kajian lepas oleh penulis antarabangsa dan tempatan. Seterusnya bahagian 3, iaitu metodologi kajian, bahagian 4 memberi fokus kepada dapatan kajian serta perbincangan dan bahagian terakhir, iaitu kesimpulan dan cadangan dasar.

\section{SOROTAN KAJIAN LEPAS}

Faktor-faktor yang mempengaruhi prestasi pekerja merupakan antara kajian yang penting dalam bidang pengurusan sumber manusia. 
Ini kerana prestasi pekerja memberi kesan secara langsung kepada prestasi sesebuah organisasi. Kajian oleh Anastasios dan Prodomos (2018) menggunakan kaedah persamaan model struktur mendapati persekitaran kerja dan sokongan pihak pengurusan memberi impak yang paling tinggi terhadap prestasi pekerja industri kecil dan sederhana. Prihatini (2016) menganalisis penentu prestasi pekerja berdasarkan proses pembangunan modal insan melalui analisis kuantitatif dengan populasi ialah semua pekerja di syarikat ketiga terbesar, dan menggunakan analisis komponen utama. Hasil kajian mendapati tiga faktor yang paling dominan ialah pengembangan modal manusia, kepimpinan, dan pekerja sumber luar. Iskandar, Ahmad dan Martua (2014) pula mengkaji penentu prestasi pekerja di Bank Islamik di Indonesia dengan menggunakan kaedah kuantitatif dan melibatkan 32 responden. Hasil kajian mereka mendapati bahawa prestasi pekerja dipengaruhi oleh faktor tekanan kerja, motivasi dan komunikasi.

Motivasi merupakan faktor yang mendorong seseorang untuk melakukan sesuatu. Motivasi merupakan sebuah daya yang membolehkan seseorang bertindak dalam arah tujuan tertentu. Motivasi pekerja mencerminkan tahap tenaga, komitmen dan kreativiti yang ditunjukkan oleh pekerja dalam kerja mereka (Shahzadi, Javed, Pirzada, Nasreen dan Khanam, 2014). Nabi, Islam, dan Al Hossain (2017) mendefinisikan motivasi merupakan suatu proses yang bermula dengan kekurangan fisiologi atau keperluan yang mengaktifkan tingkah laku seseorang untuk mencapai matlamat. Motivasi terdiri daripada tiga teras elemen yang saling bergantungan, iaitu keperluan, pemacu dan insentif. Elvina dan Liu (2019) pula mendefinisikan motivasi sebagai pendorong yang mempengaruhi tindakan individu untuk mencapai matlamat peribadi dan organisasi. Wujudnya motivasi, prestasi kerja dapat ditingkatkan. Motivasi dipengaruhi oleh faktor luaran (extrinsic) dan dalaman (intrinsic). Motivasi intrinsik hadir apabila seseorang mempunyai minat dan menyukai kerja yang dilakukan. Individu yang memiliki motivasi ini mempunyai keinginan untuk meneroka peluang baru, menyukai cabaran dan menimba pengalaman dan ilmu pengetahuan serta mencapai kepuasan. Individu yang mempunyai motivasi ekstrinsik pula didorong oleh faktor luar diri mereka seperti tertarik dengan ganjaran, insentif yang ditawarkan atau takut dikenakan hukuman (Maryam, Ashique dan Sameena, 2017). 
Dapatan kajian oleh Kalhoro, Jhatial dan Khokhar(2017) menunjukkan bahawa kedua-dua motivasi luaran dan dalaman ialah penting untuk meningkatkan prestasi serta komitmen pekerja terhadap organisasi. Seterusnya, Nabi et al. (2017) mendapati bahawa elemen-elemen motivasi kerja, iaitu motivasi luaran, kerja pengkayaan dan penilaian kerja, kuasa untuk membuat keputusan dan peluang pertumbuhan dapat meningkatkan prestasi kerja dan mencapai matlamat organisasi. Shahzadi et al. (2014) menyatakan bahawa apabila pekerja mempunyai motivasi dalaman, motivasi kerja dan prestasi kerja akan meningkat. Selain itu, Makki dan Abid (2017) dalam kajian mereka mendapati bahawa prestasi kerja lelaki dan wanita didorong oleh motivasi luaran tetapi wanita lebih cenderung mempunyai motivasi dalaman yang lebih tinggi berbanding lelaki. Pengkaji Shaikh, Pathan dan Khoso (2018) mendapati bahawa prestasi pekerja di industri makanan dan tekstil di Pakistan didorong oleh motivasi luaran seperti polisi syarikat, jaminan kerja, penyeliaan, wang, persekitaran kerja dan hubungan dengan rakan sekerja.

Selain itu, persekitaran tempat kerja dilihat dari pelbagai sudut seperti persekitaran kerja fizikal, pengaruh rakan sekerja, hubungan dengan majikan, matlamat syarikat, keadaan kerja dan sebagainya. Menurut Health (2006), persekitaran tempat kerja melibatkan lokasi fizikal serta persekitaran, prosedur, dasar, peraturan, budaya, sumber, hubungan kerja, lokasi kerja dan semua yang mempengaruhi cara pekerja melaksanakan kerja mereka. Al-Omari dan Okasheh (2017) menyatakan bahawa persekitaran kerja ialah keadaan luaran dan dalaman yang mempengaruhi keadaan kerja yang menyebabkan kerja diselesaikan serta-merta. Persekitaran tempat kerja berbentuk fizikal ialah lebih kepada susun atur dan reka bentuk pejabat manakala persekitaran berbentuk psikososial melibatkan keadaan kerja, kesanggupan peranan (role congruity) dan sokongan moral daripada penyelia (Samson, Waiganjo dan Koima, 2015). Persekitaran tempat kerja yang berkualiti dikatakan mampu mempengaruhi individu di sekitar organisasi dalam pelbagai cara termasuklah prestasi kerja mereka (Nur Zainie dan Narehan Hassan 2015). Persekitaran tempat kerja yang sesuai, ketidakhadiran pekerja dapat dikurangkan seterusnya meningkatkan prestasi pekerja yang akan membawa kepada peningkatan produktiviti di tempat kerja (Lankeshwara, 2016). Persekitaran tempat kerja fizikal yang tidak mengambil kira langkahlangkah keselamatan, pengudaraan, penggunaan perabot yang sesuai 
dan reka bentuk stesen kerja akan mengurangkan kepuasan pekerja yang seterusnya menyebabkan mereka mempunyai sikap untuk tidak hadir ke tempat kerja.

Malik, Ahmad, Gomez dan Ali (2011) mendapati bahawa faktorfaktor persekitaran tempat kerja seperti sokongan moral, persekitaran tempat kerja fizikal, ciri-ciri kerja, latihan dan pembangunan serta komunikasi mempengaruhi prestasi kerja. Penambahbaikan persekitaran tempat kerja bukan sahaja meningkatkan prestasi pekerja, juga meningkatkan prestasi organisasi dengan mengekalkan pekerja daripada meletak jawatan. Menurut Samson et al. (2015), faktor persekitaran tempat kerja berbentuk psikososial mempengaruhi prestasi pekerja berbanding persekitaran berbentuk fizikal. Apabila pekerja memahami peranan dan tanggungjawab masing-masing serta melaksanakan tugas dengan baik, prestasi kerja juga akan meningkat. Dapatan kajian oleh Nur Zainie dan Narehan Hassan (2015) menyatakan bahawa faktor demografi jantina dan persekitaran tempat kerja perlu diambil kira untuk meningkatkan prestasi pekerja. Oleh itu, organisasi haruslah memastikan persekitaran tempat kerja berada dalam keadaan baik agar pekerja meningkatkan produktiviti mereka serta memperoleh kepuasan.

Seterusnya, salah satu pendekatan untuk melahirkan modal manusia ialah melalui latihan dan pembangunan (Nickson, 2007). Perkara ini amat penting untuk melengkapkan diri pekerja dengan kemahiran yang diperlukan agar bersedia untuk menghadapi segala kemungkinan seperti perubahan teknologi yang bakal berlaku. Latihan merujuk kepada program yang memberi pendedahan kepada pekerja berkenaan maklumat, kemahiran baru atau peluang pembangunan profesional (Sommerville, 2007). Latihan juga merupakan suatu proses sistematik untuk meningkatkan kemahiran, pengetahuan, serta kecekapan pekerja yang diperlukan untuk melaksanakan kerja dengan baik (Elnaga dan Imran, 2013). Latihan dan pembangunan direka untuk pekerja dan pembangunan organisasi (organizational development) untuk menghadapi cabaran pada masa kini. Latihan bertujuan untuk meningkatkan pengetahuan dan kemahiran pekerja untuk prestasi yang lebih mantap (Malik et al., 2011). Karim, Choudhury dan Latif (2019) menyatakan bahawa latihan yang berorientasikan pada masa kini yang memberi penekanan kepada individu, kemahiran khusus dan kemahiran yang diperlukan segera untuk melaksanakan tugas mereka. 
Pembangunan pula merupakan suatu usaha untuk membentuk sikap, kelakuan dan meningkatkan prestasi kerja.

Latihan bertujuan untuk merapatkan jurang antara prestasi semasa dan prestasi piawai yang diingini (Elnaga dan Imran, 2013). Latihan dan pembangunan memfokuskan kepada pemahaman, pengetahuan, teknik dan amalan. Ini merupakan salah satu daripada keperluan pengurusan sumber manusia memandangkan ia dapat meningkatkan prestasi di peringkat individu, kumpulan dan organisasi (Tahir, Yousafzai, Jan dan Hashim, 2014). Latihan yang dijalankan haruslah efektif dan berkesan dalam mempengaruhi prestasi kerja. Tanpa latihan yang betul, pekerja baru dan sedia ada tidak menerima maklumat dan mengembangkan kemahiran yang diperlukan untuk melaksanakan tugas mereka dengan potensi yang maksimum (Elnaga dan Imran, 2013). Karim et al. (2019) menyatakan bahawa latihan dan pembangunan merupakan keperluan pengurusan sumber manusia yang menjadi keutamaan kepada pekerja. Dapatan kajian menunjukkan bahawa latihan dapat meningkatkan kemahiran, pengetahuan dan kebolehan pekerja serta mendapat kepuasan kerja. Tahir et al. (2014) dalam kajiannya mendapati bahawa latihan dan pembangunan secara tidak langsung memberi kesan kepada prestasi dan juga produktiviti pekerja. Latihan dan pembangunan memberi kesan yang positif kepada pekerja kerana mengambil kira penambahbaikan, pengetahuan kerja, teknik, kemahiran, kebolehan, kecekapan dan moral. Shafiq dan Hamza (2017) membuktikan bahawa apabila organisasi mengamalkan pengkayaan kerja (job enrichment), ia memberi kesan yang signifikan terhadap prestasi pekerja kerana melalui cara ini, pekerja mempunyai motivasi dan peluang untuk memaksimumkan keupayaan mereka yang seterusnya dapat meningkatkan prestasi dan produktiviti pekerja.

Hasil tinjauan sorotan kajian lepas boleh dirumuskan bahawa organisasi perlu mempertimbangkan motivasi ekstrinsik dan intrinsik yang dilihat mempunyai kepentingan yang sama rata kepada pekerja. Pekerja memerlukan kedua-dua motivasi ini untuk memaparkan prestasi kerja yang baik dalam jangka masa panjang. Motivasi ekstrinsik dilihat penting untuk menjaga kebajikan dan kepentingan pekerja serta mengekalkan mereka dalam organisasi. Sekiranya motivasi pekerja tidak dipenuhi, maka tidak hairanlah sekiranya prestasi kerja akan terjejas. Selain itu, persekitaran tempat kerja bukan sahaja mengambil kira keadaan fizikal, tetapi mementingkan interaksi antara pekerja dalam organisasi. Persekitaran tempat kerja 
yang selesa dan kondusif diperlukan untuk meningkatkan prestasi kerja. Seterusnya, pekerja memerlukan latihan dan pembangunan secara berterusan dan intensif agar kekal relevan di pasaran yang sentiasa mengalami perubahan dari masa ke masa.

Kajian lepas (seperti Iskandar et al. (2014); Maryam et al. (2017); Shafiq dan Hamza (2017)) lazimnya menggunakan kaedah kuantitatif, iaitu penggunaan model regresi untuk mengkaji impak faktor penentu terhadap prestasi pekerja. Kajian ini melaporkan komponen-komponen setiap faktor penentu yang mempengaruhi prestasi pekerja. Hasil kajian ini boleh dijadikan rujukan atau panduan kepada pengurusan sesebuah organisasi dalam merangka pelan untuk meningkatkan prestasi pekerja secara lebih terperinci. Prestasi pekerja dipengaruhi oleh pelbagai faktor dan banyak dibincangkan oleh pengkaji lepas, kajian ini menggunakan tiga faktor, iaitu motivasi, persekitaran tempat kerja dan latihan, dan pembangunan untuk melihat pengaruhnya terhadap prestasi pekerja (Rajah 1).

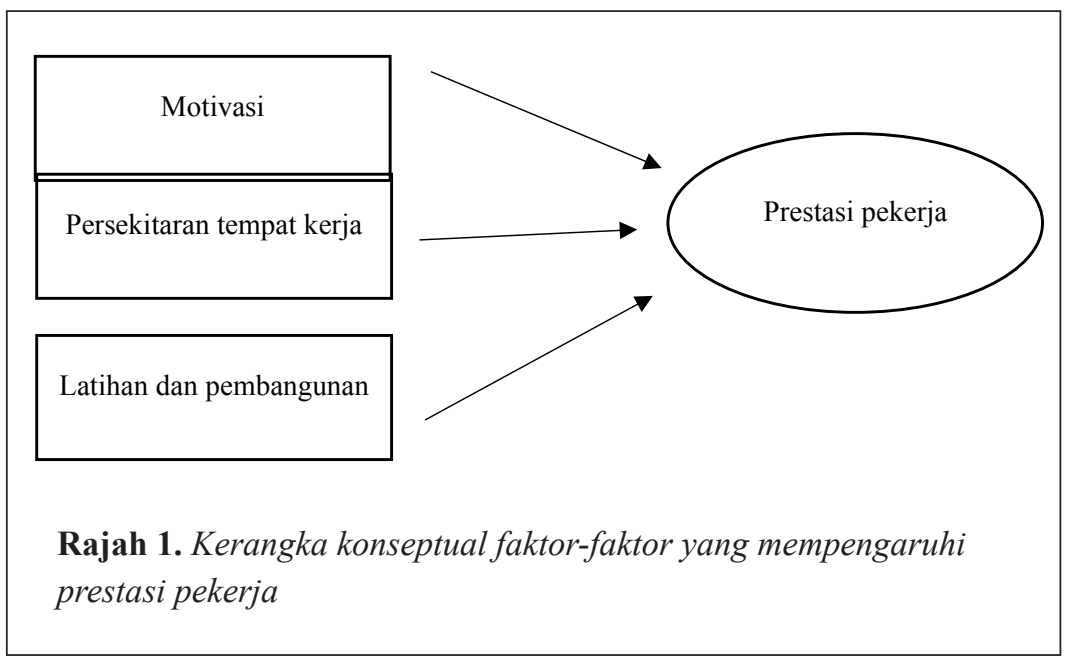

Berdasarkan teori umum prestasi (Krausert, 2009), sifat keperibadian tertentu, dan pengalaman (termasuk pengalaman praktikal, latihan, dan pendidikan) ialah faktor yang menentukan kecekapan dan prestasi seseorang pekerja. Rajah 1 menerangkan kerangka konseptual yang dibentuk dengan mengambil kira faktor motivasi, persekitaran tempat kerja serta latihan dan pembangunan sebagai pembolehubah bebas. Manakala prestasi pekerja sebagai pembolehubah bersandar. 


\section{METODOLOGI KAJIAN}

Kajian ini menggunakan data primer dan sekunder. Data primer merupakan data mentah yang dikumpul sendiri oleh pengkaji manakala data sekunder diperoleh daripada pengkaji-pengkaji lepas melalui pembacaan ilmiah, jurnal artikel daripada sumber internet (Joop dan Hennie, 2005). Kaedah tinjauan dipilih sebagai pendekatan kuantitatif dan digunakan untuk memperoleh maklumat yang menggambarkan ciri-ciri sampel individu yang besar dengan cepat (Ponto, 2015). Responden yang terlibat dalam kajian ini adalah dalam kalangan penjawat awam dan swasta di kawasan sekitar Lembah Klang, iaitu Selangor, Kuala Lumpur dan Putrajaya. Kawasan ini dipilih kerana ia merupakan kawasan tumpuan kompleks kerajaan dan syarikat swasta. Kaedah persampelan secara rawak digunakan, iaitu borang soal selidik diagihkan secara rawak kepada responden yang berjumlah 139 orang. Data Jabatan Perangkaan Malaysia melaporkan bahawa jumlah pekerja di Selangor, Putrajaya dan Kuala Lumpur ialah seramai 4,368,600 orang pada tahun 2019. Mengikut Cochran (1963), jumlah responden kajian ini mewakili tahap keyakinan 5 peratus dan selang keyakinan 8 peratus. Soal selidik diagihkan dalam dua bentuk, iaitu salinan keras dan salinan lembut berbentuk Google Form. Setiap responden diberikan kod bagi mengelakkan sebarang kemungkinan pertindihan. Menurut Williams (2007), pendekatan kuantitatif melibatkan pengumpulan data yang kebiasaannya berangka. Pendekatan ini dipilih kerana mudah untuk mengumpul data daripada bilangan responden yang ramai. Selain itu, memudahkan proses untuk menganalisis jawapan yang diberikan oleh responden untuk tujuan hasil kajian.

Soal selidik dibangunkan oleh penyelidik sendiri berdasarkan teori umum prsestasi (Krausert, 2019). Ia terdiri daripada dua bahagian iaitu Bahagian A dan Bahagian B. Bahagian A terdiri daripada tiga sub bahagian, iaitu faktor pertama (motivasi), faktor kedua (persekitaran tempat kerja) dan faktor ketiga (latihan dan pembangunan). Setiap faktor mempunyai lingkungan lapan sehingga sepuluh soalan berbentuk skala Likert dan mempunyai lima kategori jawapan, iaitu 1- sangat tidak setuju, 2-tidak setuju, 3-tidak pasti, 4-setuju dan 5-sangat setuju. Menurut Dilman, Jolene dan Leah (2014) yang dipetik daripada Willits, Theodori dan Luloff (2016), lima pilihan jawapan merupakan format umum yang paling banyak digunakan pada masa kini. Penggunaan lima pilihan jawapan ini ialah mesra pengguna dan 
didapati memberikan tahap kebolehpercayaan (reliability) yang boleh diterima. Soalan dalam bahagian B berkenaan dengan profil demografi responden. Data yang diperoleh melalui soal selidik seterusnya akan dianalisis menggunakan pakej perisian SPSS (Statistical Package for Social Sciences).

\section{DAPATAN KAJIAN DAN PERBINCANGAN}

Bahagian ini menerangkan hasil analisis kajian yang diperoleh dan perbincangan berkenaan demografi serta tiga faktor, iaitu motivasi, persekitaran tempat kerja dan latihan dan pembangunan yang mempengaruhi prestasi kerja.

\section{Jadual 1}

Profil Demografi Responden

\begin{tabular}{lcc}
\hline & Bilangan & Peratus \\
\hline Jantina & 50 & 36.0 \\
Lelaki & 89 & 64.0 \\
Perempuan & & \\
Umur & 3 & 2.2 \\
20 tahun dan ke bawah & 40 & 28.8 \\
1-30 tahun & 59 & 42.4 \\
41-40 tahun & 21 & 15.1 \\
51 tahun dan ke atas & 16 & 11.5 \\
Kaum & & \\
Melayu & 130 & 93.5 \\
Cina & 4 & 2.9 \\
India & 3 & 2.2 \\
Lan & 1 & 0.7 \\
& 1 & 0.7
\end{tabular}

Tahap pendidikan tertinggi

\begin{tabular}{lcc} 
SPM & 13 & 9.4 \\
STPM & 3 & 2.1 \\
Sijil & 4 & 2.9 \\
Diploma & 33 & 23.7 \\
Ijazah Sarjana Muda (Degree) & 65 & 46.8 \\
Ijazah Sarjana (Masters) & 19 & 13.7 \\
Doktor Falsafah (PhD) & 2 & 1.4 \\
\hline
\end{tabular}




\begin{tabular}{lcc}
\hline & Bilangan & Peratus \\
\hline Pengalaman bekerja di syarikat semasa & 16 & 11.5 \\
Kurang daripada 1 tahun & 35 & 25.2 \\
1-5 tahun & 34 & 24.5 \\
6-10 tahun & 23 & 16.5 \\
11-15 tahun & 8 & 5.8 \\
16-20 tahun & 23 & 16.5 \\
21 tahun dan ke atas & & \\
& & \\
Pendapatan (RM) & 19 & 13.7 \\
2000 dan ke bawah & 61 & 43.9 \\
2001-4000 & 31 & 22.3 \\
4001-6000 & 14 & 10.1 \\
6001-8000 & 5 & 3.6 \\
$8001-10000$ & 9 & 6.5 \\
10001 dan ke atas & & \\
Sektor pekerjaan & & 54.7 \\
Awam & 76 & 45.3 \\
Swasta & 63 & \\
\hline
\end{tabular}

Jadual 1 membincangkan maklumat demografi responden yang mengambil kira tujuh item, iaitu jantina, umur, kaum, tahap pendidikan tertinggi, pengalaman bekerja di syarikat semasa, pendapatan serta sektor pekerjaan. Sejumlah 139 responden daripada kalangan penjawat awam dan swasta di kawasan sekitar Lembah Klang terlibat dalam kajian ini. Dari segi jantina, majoriti responden ialah terdiri daripada perempuan yang mencatatkan 89 responden bersamaan 64 peratus. Manakala responden lelaki mencatatkan seramai 50 responden bersamaan 36 peratus.

Dari segi umur, majoriti responden berumur 31 hingga 40 tahun yang terdiri daripada 59 responden bersamaan 42.4 peratus. Kumpulan umur 20 tahun dan ke bawah mencatatkan 3 responden bersamaan 2.2 peratus. Kumpulan umur 21 hingga 30 tahun ialah sebanyak 40 responden bersamaan 28.8 peratus. Selain itu, kumpulan umur 41 hingga 50 tahun terdiri daripada 21 responden bersamaan 15.1 peratus. Seterusnya, kumpulan umur 51 tahun dan ke atas mencatatkan 16 responden bersamaan 11.5 peratus. Majoriti responden ialah berbangsa Melayu, iaitu seramai 130 responden bersamaan 93.5 peratus. Responden berbangsa Cina terdiri daripada 4 responden bersamaan 2.9 peratus. Kaum India pula mencatatkan 3 responden bersamaan 2.2 
peratus. Kaum Iban dan kaum-kaum lain masing-masing mencatatkan 1 responden bersamaan 0.7 peratus.

Responden yang berkelulusan diploma ialah seramai 33 responden bersamaan 23.7 peratus. Majoriti responden mempunyai tahap pendidikan Ijazah Sarjana Muda, iaitu 65 responden bersamaan 46.8 peratus. Selain itu, responden yang berkelulusan Ijazah Sarjana mencatatkan 19 responden bersamaan 13.7 peratus. Tahap pendidikan Doktor Falsafah serta STPM mencatatkan bacaan yang sama, iaitu 2 responden bersamaan 1.4 peratus. Seramai 13 responden bersamaan 9.4 peratus yang mempunyai tahap pendidikan tertinggi SPM. Selain itu, 4 responden bersamaan 2.9 peratus memiliki Sijil. Akhirnya, 1 responden bersamaan 0.7 peratus mempunyai tahap pendidikan tertinggi SPM/MCE. Seramai 16 responden bersamaan 11.5 peratus mempunyai pengalaman bekerja kurang daripada 1 tahun di syarikat semasa. Majoriti responden mempunyai pengalaman 1 hingga 5 tahun di syarikat semasa, iaitu sebanyak 35 responden bersamaan 25.2 peratus. Responden yang mempunyai pengalaman selama bekerja 6 hingga 10 tahun pula terdiri daripada 34 responden bersamaan 24.5 peratus. Responden yang mempunyai pengalaman bekerja selama 11 hingga 15 tahun serta 21 tahun dan ke atas masing-masing mencatatkan bacaan yang sama, iaitu 23 responden bersamaan 16.5 peratus. Manakala responden yang mempunyai pengalaman bekerja selama 16 hingga 20 tahun ialah seramai 8 responden bersamaan 5.8 peratus.

Responden yang mempunyai pendapatan RM2000 dan ke bawah ialah 19 responden bersamaan 13.7 peratus. Majoriti responden mempunyai pendapatan lingkungan RM2001 hingga RM4000, iaitu 61 responden bersamaan 43.9 peratus. Lingkungan pendapatan RM4001 hingga RM6000 mencatatkan sejumlah 31 responden bersamaan 22.3 peratus. Selain itu, 14 responden bersamaan 10.1 peratus mempunyai pendapatan lingkungan RM6001 hingga RM8000. Seterusnya, lingkungan pendapatan RM8001 hingga RM10000 dimiliki oleh 5 responden bersamaan 3.6 peratus. Akhirnya, 9 responden bersamaan 6.5 peratus mempunyai pendapatan RM10001 dan ke atas. Majoriti responden bekerja di sektor awam yang terdiri daripada 76 responden bersamaan 54.7 peratus. Sektor swasta pula mencatatkan seramai 63 responden bersamaan 45.3 peratus. 


\section{Jadual 2}

Faktor Motivasi

\begin{tabular}{|c|c|c|}
\hline & Min & $\begin{array}{l}\text { Sisihan } \\
\text { piawai }\end{array}$ \\
\hline Gaji mempengaruhi prestasi kerja anda & 4.1295 & 0.9312 \\
\hline $\begin{array}{l}\text { Insentif fringe benefits (faedah sampingan) yang } \\
\text { disediakan oleh syarikat seperti insurans kesihatan, } \\
\text { elaun perumahan, diskaun untuk pekerja dan } \\
\text { makanan, vacation pay (cuti bergaji), sick pay } \\
\text { (gaji sakit) dan lain-lain mempengaruhi prestasi } \\
\text { kerja anda }\end{array}$ & 4.2302 & 0.8534 \\
\hline $\begin{array}{l}\text { Ganjaran seperti bonus dan kenaikan gaji } \\
\text { mempengaruhi prestasi kerja anda }\end{array}$ & 4.3669 & 0.8266 \\
\hline $\begin{array}{l}\text { Kenaikan pangkat (promotion) dan pengiktirafan } \\
\text { (recognition) mempengaruhi prestasi kerja anda }\end{array}$ & 4.3525 & 0.8153 \\
\hline $\begin{array}{l}\text { Tindakan tatatertib yang ditetapkan oleh } \\
\text { syarikat seperti dipotong gaji dan dibuang kerja } \\
\text { mempengaruhi prestasi kerja anda }\end{array}$ & 3.7770 & 1.0771 \\
\hline $\begin{array}{l}\text { Anda bekerja untuk meningkatkan skil kemahiran } \\
\text { dan kecekapan }\end{array}$ & 4.4245 & 0.6253 \\
\hline $\begin{array}{l}\text { Anda mementingkan kemajuan (progress) dalam } \\
\text { kerja yang anda lakukan }\end{array}$ & 4.4892 & 0.6298 \\
\hline $\begin{array}{l}\text { Anda bekerja untuk memperoleh kepuasan diri } \\
\text { (satisfaction) }\end{array}$ & 4.2806 & 0.7521 \\
\hline $\begin{array}{l}\text { Anda bekerja kerana anda menyukai kerja semasa } \\
\text { (current job) anda }\end{array}$ & 4.0863 & 0.8208 \\
\hline $\begin{array}{l}\text { Anda bekerja untuk mencapai matlamat peribadi } \\
\text { (personal goals) }\end{array}$ & 3.9856 & 0.9167 \\
\hline
\end{tabular}

Jadual 2 memaparkan keputusan analisis kajian bagi faktor pertama, iaitu motivasi dalam nilai min dan sisihan piawai. Daripada jadual di atas, secara purata, kebanyakan responden bersetuju bahawa motivasi berbentuk ekstrinsik dan intrinsik mempengaruhi prestasi kerja. Dapatan kajian ini selari dengan kajian oleh Makki dan Abid (2017), dan Maryam et al. (2017). Motivasi mempengaruhi prestasi kerja kerana bertindak sebagai pencetus semangat dan dorongan kepada pekerja untuk terus meningkatkan prestasi mereka. Namun 
begitu, responden tidak pasti dengan kenyataan tindakan tatatertib seperti dipotong gaji dan dibuang kerja mempengaruhi prestasi kerja mereka yang menunjukkan nilai min sebanyak 3.7770. Hal ini kerana pekerja tidak mengambil kisah dengan hukuman yang ditetapkan oleh syarikat. Walaupun syarikat mengenakan hukuman yang berat, ia tidak mempengaruhi prestasi kerja mereka. Selain itu, nilai min sebanyak 3.9856 menunjukkan bahawa responden tidak pasti sama ada mereka bekerja untuk mencapai matlamat peribadi. Hal ini disebabkan oleh pekerja kekurangan motivasi intrinsik dalam diri mereka tetapi mempunyai motivasi ekstrinsik, iaitu terpengaruh dengan gaji dan pengiktirafan untuk meningkatkan prestasi kerja.

\section{Jadual 3}

Faktor Persekitaran Tempat Kerja

\begin{tabular}{lcc}
\hline & Min & $\begin{array}{c}\text { Sisihan } \\
\text { piawai }\end{array}$ \\
\hline $\begin{array}{l}\text { Kemudahan fasiliti di tempat kerja mempengaruhi } \\
\text { prestasi kerja anda Contoh: pendingin hawa } \\
\text { (air-conditioner), kerusi, meja, almari, kemudahan }\end{array}$ & & 0.6813 \\
$\begin{array}{l}\text { Wi-Fi dan sebagainya } \\
\begin{array}{l}\text { Tahap keselamatan di tempat kerja mempengaruhi } \\
\text { prestasi kerja anda }\end{array}\end{array}$ & 4.3525 & 0.6122 \\
$\begin{array}{l}\text { Komunikasi di tempat kerja mempengaruhi prestasi } \\
\text { kerja anda }\end{array}$ & 4.4317 & 0.6144 \\
$\begin{array}{l}\text { Perubahan pada persekitaran tempat kerja } \\
\text { mempengaruhi prestasi kerja anda }\end{array}$ & 4.2158 & 0.7098 \\
$\begin{array}{l}\text { Rakan kerja mempengaruhi prestasi kerja anda } \\
\begin{array}{l}\text { Hubungan antara pekerja dan majikan } \\
\text { mempengaruhi prestasi kerja anda di tempat kerja }\end{array}\end{array}$ & 4.4604 & 0.6838 \\
$\begin{array}{l}\text { Penetapan objektif syarikat mempengaruhi prestasi } \\
\text { kerja anda }\end{array}$ & 4.0576 & 0.7965 \\
$\begin{array}{l}\text { Keselesaan dengan suasana di tempat kerja } \\
\text { mempengaruhi prestasi kerja anda }\end{array}$ & 4.3885 & 0.6428 \\
\hline
\end{tabular}

Jadual 3 mempersembahkan keputusan analisis kajian bagi faktor kedua, iaitu persekitaran tempat kerja dalam nilai min dan sisihan 
piawai. Daripada jadual di atas, secara purata, majoriti responden bersetuju bahawa persekitaran tempat kerja mempengaruhi prestasi kerja. Dapatan kajian ini disokong kajian lepas seperti kajian oleh Malik et al. (2011), Kapur (2018) dan Nur Zainie dan Narehan Hassan (2015). Persekitaran tempat kerja mempengaruhi prestasi kerja kerana mengambil kira pelbagai perkara seperti kemudahan, hubungan dan pengaruh orang sekeliling, tahap keselamatan dan hala tuju syarikat. Apabila perkara-perkara di atas berada dalam keadaan yang baik, pekerja mempunyai semangat untuk meningkatkan prestasi kerja. Pekerja berasa selesa apabila berada di tempat kerja yang kondusif, menjadikan mereka lebih produktif, efektif dan efisien.

\section{Jadual 4}

Faktor Latihan dan Pembangunan

\begin{tabular}{lcc}
\hline & Min & $\begin{array}{c}\text { Sisihan } \\
\text { piawai }\end{array}$ \\
\hline $\begin{array}{l}\text { Latihan yang dijalankan mempunyai peluang untuk } \\
\text { kemajuan kerjaya (career advancement) }\end{array}$ & 4.0719 & 0.8899 \\
$\begin{array}{l}\text { Latihan dan pembangunan yang dijalankan } \\
\text { mempengaruhi prestasi kerja anda }\end{array}$ & 4.0935 & 0.8331 \\
$\begin{array}{l}\text { Latihan yang dijalankan meningkatkan kemahiran soft } \\
\text { skills anda }\end{array}$ & 4.1583 & 0.8188 \\
$\begin{array}{l}\text { Setelah menjalani latihan, prestasi kerja anda } \\
\text { meningkat berbanding prestasi kerja sebelumnya }\end{array}$ & 4.0935 & 0.8418 \\
$\begin{array}{l}\text { Setelah anda menyertai latihan, ilmu yang dipelajari } \\
\text { adalah berguna untuk dipraktikkan di tempat kerja }\end{array}$ & 4.1942 & 0.7883 \\
$\begin{array}{l}\text { Latihan yang dijalankan meningkatkan ilmu } \\
\text { pengetahuan anda }\end{array}$ & 4.2662 & 0.6976 \\
$\begin{array}{l}\text { Pada pandangan anda, latihan yang bersesuaian } \\
\text { dengan keperluan semasa mempengaruhi prestasi } \\
\text { kerja anda }\end{array}$ & & 0.2950 \\
$\begin{array}{l}\text { Pada pandangan anda, prestasi kerja anda tidak } \\
\text { berubah sekiranya matlamat latihan yang dijalankan } \\
\text { adalah tidak jelas }\end{array}$ & & 0.9424 \\
\hline
\end{tabular}

Seterusnya Jadual 5 memperlihatkan keputusan analisis kajian bagi faktor ketiga, iaitu latihan dan pembangunan dalam nilai min dan sisihan piawai. Daripada jadual di atas, secara purata, majoriti responden bersetuju bahawa latihan dan pembangunan mempengaruhi 
prestasi kerja. Dapatan kajian ini selari dengan kajian oleh Karim et al. (2019) dan Tahir et al. (2014). Latihan dan pembangunan mempengaruhi prestasi kerja kerana latihan mampu meningkatkan kecekapan ke tahap yang maksimum, perkembangan serta kemahiran pekerja, relevan dengan keperluan masa. Malahan, latihan merupakan pelaburan modal manusia yang memberi manfaat kepada pekerja, iaitu gaji dan kenaikan pangkat dan kepada syarikat, iaitu produktiviti. Namun begitu, didapati bahawa responden tidak pasti dengan kenyataan prestasi kerja tidak berubah sekiranya matlamat latihan adalah tidak jelas seperti yang ditunjukkan oleh nilai min sebanyak 3.9424. Hal ini kerana matlamat latihan yang mempunyai hala tuju yang tidak spesifik tidak begitu mempengaruhi prestasi kerja.

\section{KESIMPULAN}

Kajian ini mengkaji faktor-faktor yang mempengaruhi prestasi kerja dalam kalangan penjawat awam dan swasta di kawasan sekitar Lembah Klang. Hasil kajian mendapati bahawa kesemua tiga-tiga factor, iaitu motivasi, persekitaran tempat kerja dan Latihan, dan pembangunan berperanan mempengaruhi prestasi kerja. Antara cadangan dasar yang boleh dikemukakan ialah majikan perlu menekankan keperluan motivasi intrinsik kepada pekerja. Sekiranya pekerja tidak bermotivasi, majikan menghadapi kesukaran untuk mengekalkan produktiviti dan prestasi pekerja. Majikan boleh menyuntik motivasi intrinsik kepada pekerja dengan memberi kerja yang menguji diri mereka serta mewujudkan persekitaran kerja yang mencabar. Majikan yang menyediakan kerja yang berbeza-beza, pekerja akan mempunyai semangat untuk menyiapkan kerja mereka sambil memperoleh pelbagai pengalaman untuk menguruskan kerja yang diberikan dengan baik. Melalui cara ini, pekerja bukan sahaja terdorong untuk bekerja disebabkan oleh faktor luaran, tetapi disebabkan terdorong untuk mencapai matlamat diri dan kepuasan dalam setiap kerja yang dilakukan. Pekerja yang mempunyai motivasi intrinsik akan sentiasa berusaha menyiapkan kerjanya dengan bersungguh-sungguh serta memperbaiki kelemahan diri mereka. Oleh itu, majikan memerlukan pekerja yang bermotivasi untuk mengekalkan prestasi kerja yang baik.

Langkah yang seterusnya untuk meningkatkan prestasi kerja adalah dengan pihak organisasi menetapkan matlamat latihan yang 
dijalankan dengan jelas. Hala tuju latihan menentukan prestasi pekerja. Apabila matlamat kabur, prestasi kerja ialah sama dan tidak berubah. Setiap latihan yang diberikan kepada pekerja mestilah mempunyai tujuan spesifik yang ingin dicapai agar pihak organisasi tidak menanggung kos kerugian daripada latihan yang tidak memberi kesan kepada prestasi kerja. Pihak organisasi perlu menentukan jenis latihan yang diperlukan oleh pekerja mengikut kemampuan, kesesuaian dan keberkesanan. Antara latihan yang boleh diberikan seperti latihan semasa kerja (on-the-job training), latihan luar kerja (off-the-job training), mentoring, bimbingan (coaching), perantisan (apprenticeship) dan sebagainya. Seterusnya, latihan yang dijalankan perlu mempunyai sasaran dan memberi manfaat kepada organisasi dan pekerja dalam jangka pendek dan panjang. Contohnya, latihan yang mengutamakan pembangunan pekerja bukan sahaja memberi impak kepada sikap dan prestasi kerja, tetapi pada masa yang sama dapat meningkatkan produktiviti syarikat.

\section{PENGHARGAAN}

Penyelidikan ini tidak mendapat geran khusus dari mana-mana agensi pembiayaan di sektor awam atau komersial.

\section{RUJUKAN}

Al-Omari, K \& Okasheh,H.(2017). The influence of work environment on job performance: A case study of engineering company in Jordan. International Journal of Applied Engineering Research, 12(24), 15544-15550.

Anastasios, D. D. \& Prodromos, C. (2018). Factors affecting employee performance: An empirical approach. International Journal of Productivity and Performance Management, 68(1), 171193.

Cochran, W. G. (1963). Sampling Techniques, 2nd Ed., New York: John Wiley and Sons, Inc.

Dillman, Don A., Jolene. D. Smyth, and Leah M. Christian. (2014). Internet, Phone, Mail, and Mixed-Mode Surveys: The Tailored Design Method (4th Edition). Hoboken, NJ: John Wiley.

Elnaga, A. \& Imran, A. (2013). The effect of training on employee performance. European Journal of Business and Management, 5(4), 137-147. 
Elvina, S. \& Liu, Zhi Chao. (2019). A study on the relationship between employee motivation and work performance. Journal of Business and Management, 21(3), 59-68.

Haslinda, A. (2009). Evolving terms of human resource management and development. The Journal of International Social Research, 2(9), 180-186.

Heath, B. (2006). Effect of perceived work environment on employee"s job behaviour and organizational effectiveness. Journal of Applied Psychology Banarashindu, University, Varanasi.

Iqbal, A. (2010). Employee turnover: causes, consequences and retention strategies in the Saudi organizations. The Business Review, Cambridge. 16(2), 275-281.

Iskandar, M., Ahmad, F. \& Martua, R. H. 2014. Factors influencing employees' performance: A study on the Islamic banks in Indonesia. International Journal of Business and Social Science, 5(2), 73-80.

Jabatan Tenaga Kerja Semenanjung Malaysia. (2017). Laporan Pencapaian Program dan Aktiviti. September 2017.

Joop, J. H. \& Hennie, R. B. (2005). Data collection, primary vs secondary. Encyclopedia of Social Measurement. Elsevier Inc.

Kalhoro, M., Jhatial, A. A. \& Khokhar, S. (2017). Investigating the influence of extrinsic and intrinsic motivation on work performance: Study of bank officers. Global Management Journal for Academic \& Corporate Studies, 7(1), 121-129.

Kapur, R. (2018). Problems and issues at the workplace. https:// www.researchgate.net/publication/323700827_Problems and_Issues_at_the_Workplace [5 Januari 2020].

Karim, M. M., Choudhury, M. M. \& Latif, W. (2019). The impact of training and development on employees' performance: an analysis of quantitative data. Noble International Journal of Business and Management Research. 3(2), 25-33.

Krausert. A. (2009). Performance Theories. Performance Management for Different Employee Groups. Contributions to Management Science.

Lankeshwara, P. (2016). A study on the impact of workplace environment on employee's performance: with reference to the Brandix Intimate Apparel-Awissawella. International Journal of Multidisciplinary Studies, 3(1), 47-57. 
Makki, A. \& Abid, M. (2017). Influence of intrinsic and extrinsic motivation on employee's task performance. Studies in Asian Social Science. 4(1), 38-43.

Malik, M. I., Ahmad, A., Gomez, S. F. \& Ali, M. (2011). A study of work environment and employees' performance in Pakistan. African Journal of Business Management, 5(34), 1322713232.

Maryam, K., Ashique, A. J. \& Sameena, K. (2017). Investigating the influence of extrinsic and intrinsic motivation on work performance: Study of bank officers. Global Management Journal for Academic \& Corporate Studies, 7(1), 121-129.

Mohtar Abas. (2006). Menguruskan prestasi tenaga kerja (sektor awam). Jurnal Pengurusan Awam, 5(1), 35-44.

Nabi, M. N., Islam, M. M., Dip, T . M. \& Al Hossain, M. A. (2017). Impact of motivation on employee performances: A case study of Kamarsangsthan bank limited, Bangladesh. Arabian Journal of Business and Management Review, 7(1), 1-8.

Nickson, D. (2007). Human Resource Management. London: Thomson.

Nur Zainie Abd Hamid \& Narehan Hassan. (2015). The relationship between workplace environment and job performance in selected government offices in Shah Alam, Selangor. International Review of Management and Business Research, 4(3), 845-851.

Ong, Choon Hee \& Koh, Rui Jing. (2018). The influence of human resource management practices on employee performance in the manufacturing sector in Malaysia. International Journal of Human Resource Studies, 8(2), 129-147.

Ponto, J. (2015). Understanding and evaluating survey research. Journal of the Advanced Practitioner in Oncology, 6(2), 168171.

Prihatini, T. (2016). The determinants of employee performance: role of human capital development process. International Journal of Advanced Research, 4(10), 2188-2192.

Rahmah Ismail. (2018). Ekonomi Sumber Manusia. Bangi: Penerbit Universiti Kebangsaan Malaysia.

Samson, G. N., Waiganjo, M. \& Koima, J. (2015). Effect of workplace environment on the performance of commercial banks employees in Nakuru Town. International Journal of Managerial Studies and Research, 3(12), 76-89. 
Shafiq, S. \& Hamza, S. M. (2017). The effect of training and development on employee performance in private company, Malaysia. International Journal of Education, Learning and Training, 2(2), 42-56.

Shahzadi, I., Javed, A., Pirzada, S.S., Nasreen, S. \& Khanam, F. (2014). Impact of employee motivation on employee performance. European Journal of Business and Management, 6(23), 159-166.

Shaikh, S. H., Pathan, S. K. \& Khoso, I. (2018). The impact of extrinsic motivation on employees' performance: a comparative analysis of food and textile industries in Sindh, Pakistan. International Business Research, 11(12), 61-66.

Sommerville, K. L. (2007). Hospitality Employee Management and Supervision, Concepts and Practical Applications. New Jersey: John Wiley \& Sons.

Strebler, M. (2005). Tackling poor performance. Institute for Employment Studies.

Tahir, N., Yousafzai, I. K., Jan, S. \& Hashim, M. (2014). The impact of training and development on employee's performance and productivity - a case study of United Bank Limited Peshawar City, KPK, Pakistan. International Journal of Academic Research in Business and Social Sciences, 4(4), 86-98.

Todaro, M. P. \& Smith, S. C. (2015). Economic Development. Edisi ke-12. United States of America: Pearson.

Vosloban, R. I. (2012). The influence of the employee's performance on the company's growth - a managerial perspective. Procedia Economics and Finance, 3, 660-665.

Williams, C. (2007). Research Methods. Journal of Business \& Economic Research, 5(3), 65-72.

Willits, F. K., Theodori, G. L. \& Luloff, A. E. (2016). Another look at likert scales. Journal of Rural Social Sciences, 31(3), 126-139. 